\title{
Validation of MCNPX with Experimental Results of Mass Attenuation Coefficients for Cement, Gypsum and Mixture
}

\author{
Huseyin Ozan Tekin ${ }^{1, *}$, Viswanath P. Singh ${ }^{2}$, Tugba Manici ${ }^{3}$, Elif Ebru Altunsoy ${ }^{4}$ \\ ${ }^{1}$ Department of Radiotherapy, Uskudar University, Istanbul, Turkey; ${ }^{2}$ Department of Physics, Karnatak University, Dharwad, India; ${ }^{3}$ Medical Radiation \\ Research Center (USMERA), Uskudar University, Istanbul, Turkey; ${ }^{4}$ Department of Medical Imaging, Uskudar University, Istanbul, Turkey
}

\section{Original Research}

Received May 31, 2017

Revision July 10, 2017

Accepted July 12, 2017

Corresponding author:

Huseyin Ozan Tekin

Uskudar Universitesi SHMYO Carsi Yerleskesi, Mimar Sinan Mah., Selmani Pak Caddesi, Istanbul 34672, Turkey

Tel: +90-545-501-88-43

Fax: +90-216-400-22-22

E-mail: huseyinozan.tekin@uskudar.edu.tr

This is an Open-Access article distributed under the terms of the Creative Commons Attribution NonCommercial License (http://creativecommons.org/ licenses/by-nc/4.0) which permits unrestricted noncommercial use, distribution, and reproduction in any medium, provided the original work is properly cited.

Copyright $\odot$ 2017The Korean Association for Radiation Protection

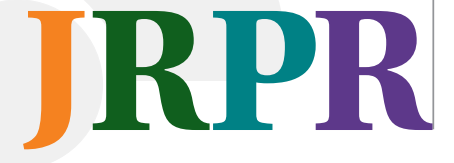

Background: Shielding properties of compound or mixture is presented in terms of mass attenuation coefficients using Monte Carlo simulation. Mass attenuation coefficients of cement, gypsum and the mixture of gypsum and $\mathrm{PbCO}_{3}$ has been investigated using monte carlo MCNPX.

Materials and Methods: The mass attenuation coefficients of cement, gypsum and the mixture of gypsum and $\mathrm{PbCO}_{3}$ were calculated for photon energies 365.5, 661.6, 1,173.2, and $1,332.5 \mathrm{keV}$ energies.

Results and Discussion: The simulated values of mass attenuation coefficients were compared avaialable experimental results, theoretical values by XCOM and found good comparability of the results.

Conclusion: Standard simulation geometry used in the present investigation would be very useful for various types of sample for shielding and dosimetry applications.

Keywords: Monte Carlo simulation, MCNPX code, Mass attenuation coefficient

\section{Introduction}

The use of materials for shielding applications is increasing day-by-day for medical, reactors, accelerators, industries, agriculture, space, etc. Choice of materials selection is dependent upon the requirement for exposure rate reduction, type of source, space constrains and final cost effective analysis. Cement, gypsum and lead are common and very useful material in the field of nuclear engineering for shielding applications. These materials are being used for purpose of construction of building of nuclear facility and direct shielding applications. Various researchers have theoretical and experimental investigations for radiation interaction with these materials and proposed various applications. Experimetal investigation requires not only mateirals, radiation sources and expermental setup of very high finatial budget but also radiation exposure to involved personnel. However, simulation method for investigation of radiation interaction is found radiologically safer, less time consuming, cost effective and applicable for desired energy of radiation. It is found that Monte Carlo simulation is suitable method for investigation of radiation interaction with materials in various literature elsewhere [1]. Mass attenuation coefficient is fundamental property of a material for photon interaction to 
represent interaction and shielding effectiveness. Mass attenuation coefficient of a element is found to be constant at particular photon energy, whereas mass attenuation coefficient of a compound or mixture depends upon composition of elements. The linear attenuation coefficient, half-value layer thickness, tenth-value layer thickness and effective atomic number are derived parameters from mass attenuation coefficient. This study aimed validation of MCNPX (version 2.4.0) code for investigation of mass attenuation coefficients of compounds and mixtures. The investigation was carried out for interaction of gamma radiation with cement, gypsum and mixture of $\mathrm{PbCO}_{3}$ with cement and gypsum at energies 365.5, $661.6,1,173.2$, and 1,332.5 keV. Simulated results were compared with available experimental data and found comparable in literature. The present investigation using standard simulation geometry for MCNPX (version 2.4.0) code would be very useful for studies of photon interraction with various types of samples for shielding and dosimetry applications.

\section{Materials and Methods}

\section{MCNPX code}

In this study, MCNPX (version 2.4.0) Monte Carlo code has been used for investigations on mass attenuation coefficients of cement, gypsum and the mixture of gypsum and $\mathrm{PbCO}_{3}$. MCNPX is a general purpose radiation transport code for modeling the interactions of radiation with materials and also tracks all particles at wide range energies. MCNPX is fully three-dimensional and it utilizes extended nuclear cross section libraries and uses physics models for particle types [2]. Validation of MCNPX code have been studied by considering the different applications in the field of radiation [3-11]. In present simulation, each simulation parameters have been defined in input file by considering the material properties and experimental setup. In this study, an isotropic radiation source has been defined and located at the beginning of the collimator. To avoid the backscatter into detection point, full collimation from radiation source point until the target shielding material was provided. Afterwards, energetic photons have interacted with target shielding material. Transmitted photons and their numerical quantities have been calculated in detection field. The simulation geometry of mass attenuation coefficient calculations can be seen in Figure 1. The geometrical forms and physical parameters for simulation have been defined in cell card and surface card of MCNPX input file. On the other hand, source

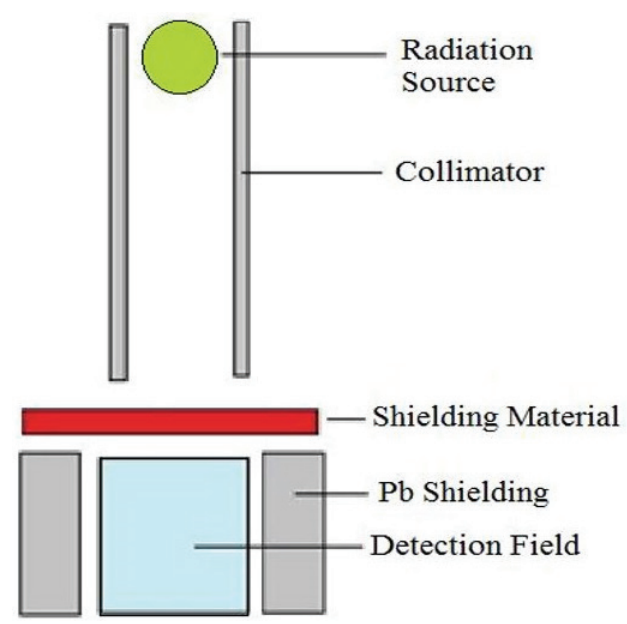

Fig. 1. MCNPX Total simulation geometry for calculations mass attenuation coefficients.

definition has been defined with different variables such as CEL, ERG, DIR, POS, and PAR. The energy source has been defined as a point source on the central axis as well. To obtain the average cell flux in defined detection area, mesh tally (type F4) has been used. This type of tally in MCNPX code reports the sum of the contributions in considered cell. This type of tally in MCNPX scores energy deposition data in which energy deposited per unit volume from all particles is included. MCNPX calculations were completed by using Intel $^{\circledR}$ Core $^{\mathrm{TM}}$ i7 CPU $2.80 \mathrm{GHz}$ computer hardware.

\section{Theoretical estimation}

In present work, following formulae were used to determine the mass attenuation coefficients for compound and composite materials. When a beam of monochromatic gamma photons is attenuated on matter according to LambertBeer law:

$$
I=I_{0} \cdot e^{-\mu t}
$$

Where, $I_{0}$ and $I$ are the incident and transmitted photon intensities, respectively, $\mu\left(\mathrm{cm}^{-1}\right)$ represents linear attenuation coefficient of the material and $t(\mathrm{~cm})$ is the thickness of the target material/sample. Rearrangement of Equation 1 yields the following equation for the linear attenuation coefficient:

$$
\mu=\frac{1}{t} \ln \left(\frac{I_{0}}{I}\right)
$$

The mass attenuation coefficients of the materials were calculated using the following equation. 


$$
\mu / \rho=\sum_{i} w_{i}\left(\mu_{m}\right)_{i}
$$

Where, $w_{i}$ is the weight fraction, $(\mu / \rho)$ is the mass attenuation coefficient of the material, $\mu_{m}$ is mass attenuation coefficient of element. The $w_{i}$ can be defined as follows:

$$
w_{i}=\frac{n_{i} A_{i}}{\sum_{i} n_{i} A_{i}}
$$

Where, $A_{i}$ is the atomic weight of the sample, $n_{i}$ is a number of formula units.

\section{Validation}

Applying the Monte Carlo method is the one of the best solution for the investigation of different complex material behaviors since experimental duplication of investigation is quite complicated. So, it is more suitable to apply some numerical methods such as Monte Carlo [12]. In this paper, a validation for input code was performed. On the other hand, WinXcom program was also used to calculate the gamma ray mass attenuation coefficients of the studied shielding materials. WinXcom $[13,14]$ program is a user friendly calculation program and input parameter specifications are quite flexible and easy to access. In the WinXcom program, firstly, shielding material types were defined by their elemental mass fractions, which are totally the same as in MCNPX Monte Carlo code input. Secondly, the gamma ray energies have been defined. The attenuation coefficients of the selected materials were finally calculated by the program.

\section{Results and Discussion}

MCNPX simulation input has been used for mass attenuation coefficients calculations of cement, gypsum and the mixture of gypsum and $\mathrm{PbCO}_{3}$ materials. The mass attenuation coefficients for attenuator samples doped by different percentages of $\mathrm{PbCO}_{3}$ were calculated for the four different energies 356, 662, 1,173, and 1,333 keV and shown in Figure 2. The standard XCOM data has been used for comparison
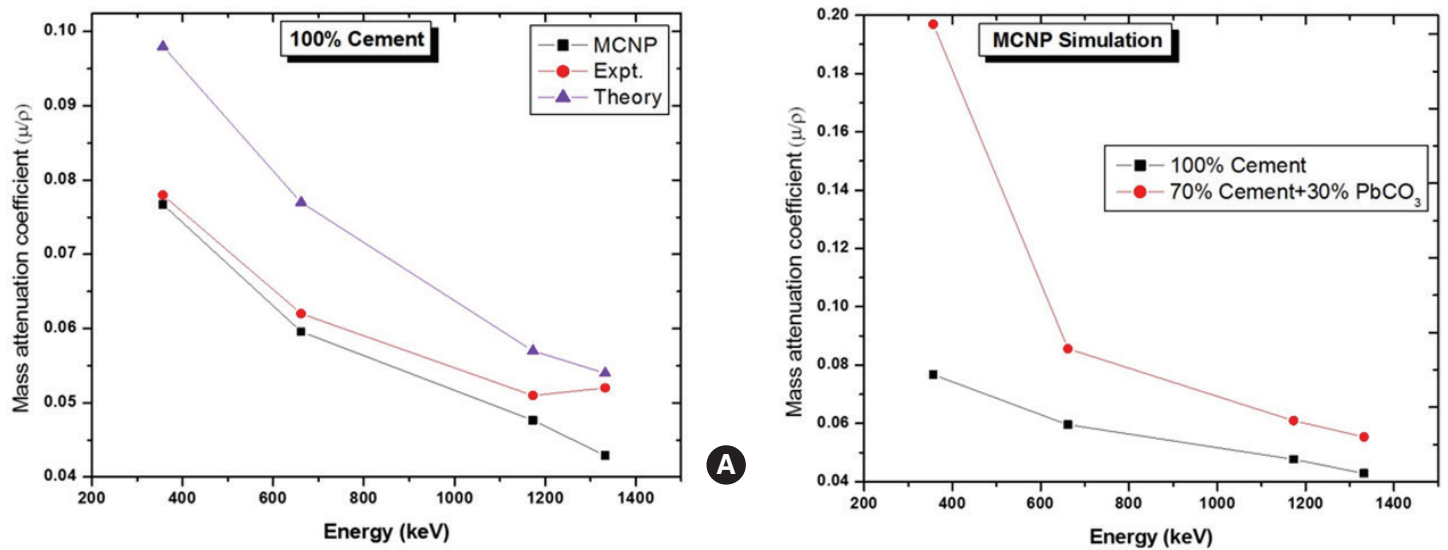

B
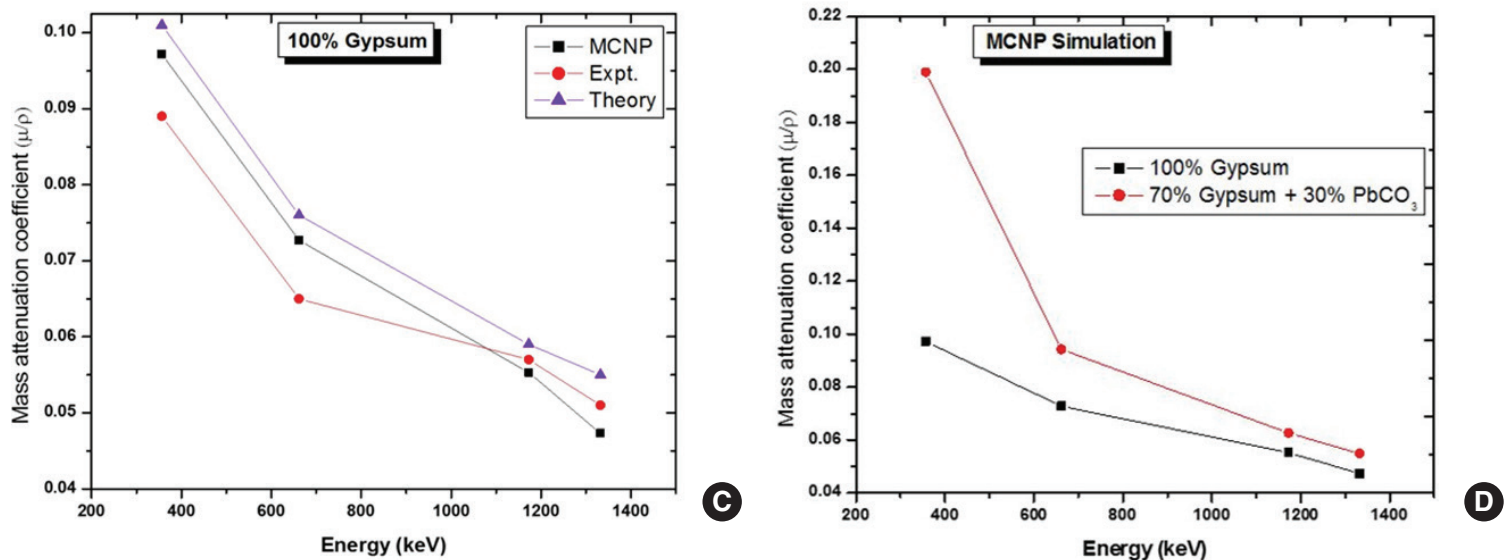

Fig. 2. Mass attenuation coefficients of cements and gypsum. (A) 100\% cement, (B) $30 \% \mathrm{PbCO}_{3}+70 \%$ cement, (C) 100\% gypsum, and (D) $30 \% \mathrm{PbCO}_{3}+70 \%$ gypsum. 
with obtained MCNPX results. Figure 2 shows mass attenuation coefficinents of cement, gypsum and small doping of $\mathrm{PbCO}_{3}$ in both the shielding materials. It is found that the mass attenuation coefficients of pure and doped cement or gypsum are decreasing with increase in photon energy. This variation of mass attenuation coefficients can be explained using fundamental photon interaction process of photoelectric effect, compton effect and pair production for low-, intermediate- and high energy photons, respectively, which varies with atomic number of elements of compostions. From Figure 2A and 2C, it is to be noted that the mass attenuation coefficients of $100 \%$ cement and $100 \%$ gypsum estimated using MCNPX is lesser than theoretical data and comparable with experimental results. However, from Figure $2 \mathrm{~B}$ and $2 \mathrm{D}$ it is observed that using MCNPX simulation, the mass attenuation coefficients of $100 \%$ cement and gypsum are lesser than $30 \%$ doping of $\mathrm{PbCO}_{3}$. Doped cement and gypsum with $\mathrm{PbCO}_{3}$ are found with large difference of mass attenuation coefficients at low energy (photoelectric effect region) compared with high energy (pair production region). It is because of $\mathrm{Pb}$ element of $\mathrm{PbCO}_{3}$, which dominant for interaction in photoelectric effect region (interaction cross sectioin $\left.\alpha Z^{4-5}\right)$.

\section{Conclusion}

Mass attenuation coefficients of cement, gypsum and the mixture of gypsum and $\mathrm{PbCO}_{3}$ has been investigated using monte carlo MCNPX. The simulated values of mass attenuation coefficients were compared available experimental results, theoretical XCOM values and found good comparability of the results. Standard simulation geometry for sample prepration of the present investigation would be very useful for various types of photon interaction investigations using MCNPX without experimental analysis for pure and mixture of elements. In addition, radiation safety inside medical areas, research centers, houses, nuclear shelters especially those close to nuclear power stations can be estimated by the calculation of shielding features of common cement and gypsium mixture materials.

\section{References}

1. Dong MG, Sayyed MI, Lakshminarayana G, Çelikbilek Ersundu M, Ersundu AE, Nayar P, et al. Investigation of gamma radiation shielding properties of lithium zinc bismuth borate glasses using XCOM program and MCNP5 code. J. Non-Cryst. Solids. 2017;468:12-16.

2. RSICC Computer Code Collection. MCNPX User's Manual Version 2.4.0. LA-CP-02-408. Los Alamos National Laboratory. 2002;1-2.

3. Akkurt I, Tekin HO, Mesbahi A. Calculation of detection efficiency for the gamma detector using MCNPX. Acta Phys. Pol. A. 2015;128(2):332-334.

4. Tekin HO, Manici T. Simulations of mass attenuation coefficients for shielding materials using the MCNP-X code. Nucl. Sci. Tech. 2017;28:95.

5. Tekin HO, Manici T, Ekmekci C. Investigation of backscattered dose in a computerized tomography (CT) facility during abdominal CT scan by considering clinical measurements and application of Monte Carlo method. J. Health Sci. 2016;4:131-134.

6. Tekin HO, Singh VP, Manici T. Effects of micro-sized and nanosized $\mathrm{WO}_{3}$ on mass attenuation coefficients of concrete by using MCNPX code. Appl. Radiat. Isot. 2017;121:122-125.

7. Tekin HO, Manici T, Singh VP. An investigation on shielding effect of bismuth on lung CT scan using Monte Carlo simulation. J. Polytech. 2016;19(4):617-622.

8. Tekin HO, Singh VP, Altunsoy EE, Manici T, Sayyed MI. Mass attenuation coefficients of human body organs using MCNPX Monte Carlo code. Iranian J. Med. Phys. In press. DOI: 10.22038/ ijmp.2017.23478.1230.

9. Sayyed MI, Al-Zaatreh MY, Dong MG, Zaid MHM, Matori KA, Tekin HO. A comprehensive study of the energy absorption and exposure buildup factors of different bricks for gamma-rays shielding. Results Phys. In press. DOI: https://doi.org/10.1016/ j.rinp.2017.07.028.

10. Dong MG, El-Mallawany R, Sayyed MI, Tekin HO. Shielding properties of $80 \mathrm{TeO}_{2}-5 \mathrm{TiO}_{2}-(15-\mathrm{x}) \mathrm{WO}_{3}-\mathrm{xA}_{\mathrm{n}} \mathrm{O}_{\mathrm{m}}$ glasses using WinXCom and MCNP5 code. Radiat. Phys. Chem. 2017;141:172178.

11. Lakshminarayana G, Baki SO, Kaky KM, Sayyed MI, Tekin HO, Lira A, Kityk IV, Mahdi MA. Investigation of structural, thermal properties and shielding parameters for multicomponent borate glasses for gamma and neutron radiation shielding applications. J. Non-Cryst. Solids. 2017;471:222-237.

12. Rodenas J, Martinavarro A, Rius V. Validation of the MCNP code for the simulation of Ge-detector calibration. Nucl. Instrum. Methods Phys. Res., Sect. A. 2000;450(1):88-97.

13. Gerward L, Guilbert N, Jensen KB, Levring H. X-ray absorption in matter. Reengineer in Xcom. Radiat. Phys. Chem. 2001;60(12):23-24.

14. Gerward L, Guilbert N, Jensen KB, Levring H. WinX Com a program for calculating X-ray attenuation coefficients. Radiat. Phys. Chem. 2004;71(3):653-654. 